\title{
A Dual-Polarization Switched Beam Patch Antenna Array for Millimeter-Wave Applications
}

\author{
Kirill Klionovski, Mohammad S. Sharawi, Senior Member, IEEE, and Atif Shamim, Senior Member, IEEE
}

\begin{abstract}
Increasing data transfer rates for future millimeter-wave communications require high capacity radio channels and user-centric communication network environments. Therefore, special requirements, such as wide-angle beam steering, wide operational frequency bandwidth and simultaneous operation with orthogonal polarizations are essential for telecommunication antennas. In this paper, we present a compact patch antenna array with a Butler matrix feed network for the frequency band of 26-31.4 GHz. The 16-element planar array has been designed to operate with two linear orthogonal polarizations and provide $\pm 42^{\circ}$ beam switching. To ensure wideband operation, a novel combination of planar couplers, crossovers and phase shifters is designed to form the Butler matrix. A new phase shifter topology is used which is based on a combination of open-short stubs and Shiffman phase shifter. The design is fabricated on a low-cost multi-layer board with a size of 120x70x1.62 $\mathrm{mm}^{3}$. The size of the feeding network, which is implemented on a single board, is $76 \times 23 \times 0.1 \mathrm{~mm}^{3}$. Experimental measurements of return loss, mutual coupling and radiation patterns confirm simulated results.
\end{abstract}

Index Terms-Millimeter-wave antenna array, wideband antenna array, Butler matrix.

\section{INTRODUCTION}

Future wireless telecommunication standards are expected to address the increasing demand in bandwidth (BW) and higher data transfer rates and will operate at millimeter-wave (mm-wave) frequency bands. For example, future Local Multipoint Distribution Service (LMDS) standard promises to cover the following bands: 27.5-28.35, 29.1-29.25, and 31-31.3GHz [1], therefore, operational BW covering all the bands is more than $13 \%$. Also, the telecommunication standards require adaptive antenna arrays that are capable of wide-angle beam steering $[2,3]$ to provide optimal speeds for devices, thereby creating a user-centric environment. If these arrays can operate with two orthogonal linear polarizations, the channel capacity can be enhanced and thus the spectral efficiency of communication links can be boosted.

Designing an antenna that operates with two orthogonal linear polarizations and provides beam-steering with a BW of more than $13 \%$ is quite challenging. For beam steering, there are two popular choices, (1) an active antenna array, and (2) a switched-beam antenna array. Although active components for millimeter-wave adaptive antenna arrays are commercially available [4, 5], the use of switched-beam antennas based on a beamforming network (BFN), such as Butler matrix (BM) or Rotman lens, can be a cheaper alternative at the cost of a larger size.

In recent years, some designs of dual-polarized antenna arrays with BM BFN were reported in [6-8]. Those designs consist of two separate BM BFN for each polarization. Therefore, a single polarized antenna array with BM BFN can be extended to a dual-

This publication is based upon work supported by the King Abdullah University of Science and Technology (KAUST) Office of Sponsored Research (OSR) under Award No. OSR-2016-KKI-2899.

K. Klionovski and A. Shamim are with the King Abdullah University of Science and Technology (KAUST), Thuwal, 23955-6900, Kingdom of Saudi Arabia (e-mail: kirill.klionovski@kaust.edu.sa, atif.shamim@kaust.edu.sa).

M. S. Sharawi was with King Fahd University of Petroleum and Minerals (KFUPM), Dhahran, Saudi Arabia. Now he is with the Department of Electrical Engineering, Poly-Grames Research Center, Polytechnique Montréal, Montréal, QC H3T 1J4, Canada (e-mail: mohammad.sharawi@polymtl.ca). polarization mode through the second separate BFN and radiating elements that support dual-polarization mode. Some designs of mmwave antenna arrays based on single layer BM BFN were reported recently in [9-16]. A comparison of important parameters such as practical implementation of $\mathrm{BFN}$, impedance $\mathrm{BW}$, polarization, electrical size, efficiency and beam switching angle range has been

TABLE I

COMPARISON OF BUTLER MATRIX BASED ANTENNA ARRAYS

\begin{tabular}{||c|c|c|c|c|c|c|c|c||}
\hline \hline Paper & $\begin{array}{c}\text { BFN } \\
\text { type }\end{array}$ & Pol & $\begin{array}{c}\text { Size, } \\
\lambda\end{array}$ & $\begin{array}{c}f_{0}, \\
\mathrm{GHz}\end{array}$ & $\begin{array}{c}\mathrm{BW}, \\
\%\end{array}$ & $\begin{array}{c}\text { Eff, } \\
\%\end{array}$ & $\begin{array}{c}\text { SLL } \\
\mathrm{dB}\end{array}$ & BSR \\
\hline$[6]$ & $\mathrm{M}$ & $\mathrm{DL}$ & $\mathrm{NA}$ & 10 & 6 & 51 & 6 & $\pm 38^{\circ}$ \\
\hline$[7]$ & $\mathrm{M}$ & $\mathrm{DC}$ & $\mathrm{NA}$ & 7.83 & 15 & $\mathrm{NA}$ & 8 & $\pm 40^{\circ}$ \\
\hline$[8]$ & $\mathrm{M}$ & $\mathrm{DC}$ & $\mathrm{NA}$ & $\begin{array}{c}1.58 \\
2.2\end{array}$ & $\begin{array}{c}8 \\
9\end{array}$ & $\begin{array}{c}\text { NA } \\
\text { NA }\end{array}$ & 6.5 & $\begin{array}{c} \pm 45^{\circ} \\
\pm 42^{\circ}\end{array}$ \\
\hline$[9]$ & $\mathrm{M}$ & $\mathrm{L}$ & $\mathrm{NA}$ & 43 & $\mathrm{NA}$ & $\mathrm{NA}$ & 7 & $\pm 31^{\circ}$ \\
\hline$[10]$ & $\mathrm{M}$ & $\mathrm{L}$ & $2.4 \times 2$ & 62.4 & 8.5 & $\mathrm{NA}$ & 8 & $\pm 40^{\circ}$ \\
\hline$[11]$ & $\mathrm{M}$ & $\mathrm{L}$ & $\mathrm{NA}$ & 60.5 & 11.5 & $\mathrm{NA}$ & 5 & $\pm 40^{\circ}$ \\
\hline$[12]$ & $\mathrm{M}$ & $\mathrm{L}$ & $2.75 \times 2.5$ & 61 & 13.5 & $\mathrm{NA}$ & 7 & $\pm 40^{\circ}$ \\
\hline$[13]$ & $\mathrm{M}$ & $\mathrm{L}$ & $2 \times 2$ & 60.2 & 11.6 & $\mathrm{NA}$ & 7 & $\pm 40^{\circ}$ \\
\hline$[14]$ & $\mathrm{SIW}$ & $\mathrm{L}$ & $\mathrm{NA}$ & 61 & 11.5 & $\mathrm{NA}$ & 8 & $\pm 41^{\circ}$ \\
\hline$[15]$ & $\mathrm{SIW}$ & $\mathrm{L}$ & $6 \times 2.5$ & 30 & 13.3 & $\mathrm{NA}$ & 7.5 & $\pm 51^{\circ}$ \\
\hline$[16]$ & $\mathrm{M}$ & $\mathrm{L}$ & $2.5 \times 5$ & 27.9 & 2 & $\mathrm{NA}$ & 6.5 & $\pm 32^{\circ}$ \\
\hline $\begin{array}{c}\text { This } \\
\text { work }\end{array}$ & $\mathrm{M}$ & $\mathrm{DL}$ & $2.4 \times 1.9$ & 28.7 & 19 & 36 & 8 & $\pm 42^{\circ}$ \\
\hline \hline
\end{tabular}

BFN type - microstrip (M) or Substrate integrated waveguide (SIW) implementation of BM BFN; Pol - operating polarizations: dual linear (DL), dual circular (DC), or linear (L); Size - overall size of BFN in fractions of center operating wavelength $(\lambda) ; f_{0}$ - central operation frequency; Eff efficiency; and beam switching angles range (BSR).

done in Table I. From the comparison, we can see that antenna arrays with BM BFN published in $[7,12,15]$ can cover $13 \%$ impedance $\mathrm{BW}$, but all those BFN designs are characterized by huge amplitude $(>4 \mathrm{~dB})$ and phase $\left(>20^{\circ}\right)$ imbalances, as well as low isolation $(<12$ $\mathrm{dB}$ ) between output ports of the BFN inside the operational impedance BW. Such imbalances and isolation lead to asymmetrical beams with increased SLL, thus making the steering angle range narrower. Therefore, we are interested not only to get wide operational impedance $\mathrm{BW}$, but also to get stable radiation patterns at all operation frequencies.

In this paper, we present a novel switched-beam planar patch antenna array with dual polarization for future mm-wave applications. The beam switching is achieved through the use of a wideband BM. The wideband operation covering $26-31.4 \mathrm{GHz}$ is achieved by using novel wideband crossovers, couplers and phase shifters along with dual-fed superstrate loaded radiating patches. The planar patch antenna array consists of 16 elements (in 4 x 4 arrangement). Such arrangement is chosen to get the highest antenna area efficiency for a massive multiple-input multiple-output (MIMO) system [17]. Good agreement is achieved between the simulated and measured results. The antenna array demonstrates beam switching for angles of $\pm 42^{\circ}$ with a maximum gain of $12 \mathrm{dBi}$ and $19 \% \mathrm{BW}$. The obtained $8 \mathrm{~dB}$ SLL is comparable with the published designs and is sufficient for most mobile telecommunication system applications [3]. 


\section{Elements of The Antenna Array}

A typical scheme of a 4-beam Butler matrix contains four 3-dB quadrature directional couplers, two crossovers, two $45^{\circ}$ and two $0^{\circ}$ phase shifters. The purpose is to feed the neighboring antenna elements with equal amplitudes and equally varying phase shifts. Different phase shifts $\left( \pm 45^{\circ}\right.$ and $\left.\pm 135^{\circ}\right)$ appear when different ports are excited, and that causes the beam to switch in different directions.

Many papers have previously been published on the topic of Butler matrix, however most of these papers present multilayer designs (for example, [18]) to increase the BW of the feeding network. In this work, one of the targets is to make $5 \mathrm{G}$ base station antenna array which is low-cost and that can be easily of manufactured. Due to this reason, we have employed a single layer planar design for Butler matrix feed network.

\section{A. The Design of The Wideband Quadrature 3-dB Directional Coupler}

Some designs of planar wideband $3-\mathrm{dB}$ quadrature directional couplers have been previously published in $[19,20]$. The common disadvantage of such designs is the large size and the complicated fabrication required to realize them. One of the simplest design of a $3-\mathrm{dB}$ coupler, which can offer wide BW, is an elliptic-patch quadrature-hybrid coupler (see Fig. 1a) [21, 22]. The advantages include wide BW, small size and simple fabrication in a single-layer implementation.

Although the design has been published previously, there are no recommendations on the proper selection of both the ports' positions and the eccentricity of the ellipse to get the widest BW. We have
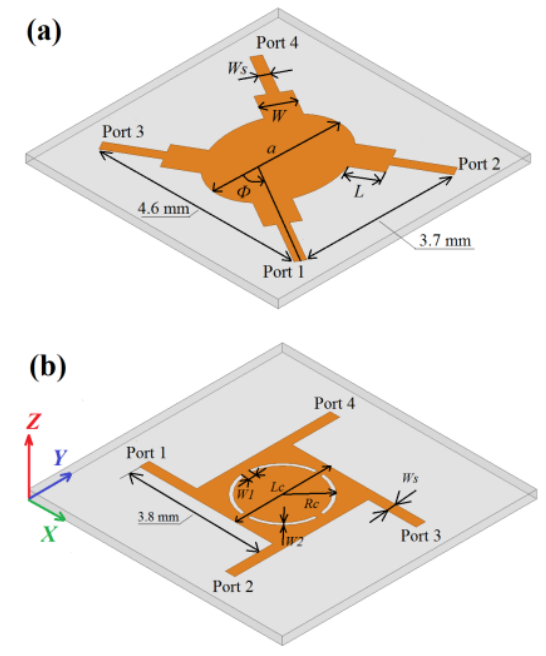

Fig. 1. (a) the wideband quadrature $3-\mathrm{dB}$ directional coupler design and (b) the wideband crossover design.

performed a parametric optimization of the $3-\mathrm{dB}$ quadrature elliptic coupler using simulations of the design in ANSYS Electromagnetic Suite V.17.2. The main conclusions of the optimization are summarized as follows.

1. Resonance frequency $f$ of the coupler is given by the equation [23] for an elliptical patch antenna:

$$
f=\frac{3 \times 10^{8} p}{a \sqrt{\varepsilon}},
$$

where $p$ is an empirical constant ranging from 0.56 to 0.6 ; $\varepsilon$ is the permittivity of the coupler's substrate; $a$ is the length of the major axis of an ellipse.
2. When the eccentricity of an ellipse is $e=1$ (the case of a disk), only $10 \%$ impedance BW can be achieved. To get $20-25 \% \mathrm{BW}$, the eccentricity should be chosen from the range of $e=0.6 \ldots 0.8$.

3 . When the coupler is fed through a $50-\Omega$ microstrip line, the feed point should be located on a radial line of the ellipse which is oriented at an azimuthal angle of $\Phi=45^{\circ}$ relative to the major axis of the ellipse. In the case of $50-\Omega$ feeding, the impedance BW is less than $15 \%$. To increase the impedance BW up to $25 \%$, the impedance of a microstrip feeding line should be decreased to $20-\Omega$. With decreasing value of the impedance, the azimuthal angle $\Phi$ should be increased to values of $\Phi=55 \ldots 65^{\circ}$.

We optimized the design for the band of 26-31 GHz. The optimized design is based on the use of a Rogers Ultralam 3850 laminate, which has a permittivity of 2.9 , loss tangent of 0.0025 , and a thickness of $0.1 \mathrm{~mm}$. We choose the parameters $p=0.59$ and $a=3.83$ $\mathrm{mm}$ in (1) to get resonance frequency of $27.1 \mathrm{GHz}$. According to the recommendations mentioned above, we choose an eccentricity of $e=0.793$ and a port angle of $\Phi=60^{\circ}$. The coupler is fed by a $20-\Omega$ microstrip line with a width of $W=0.84 \mathrm{~mm}$ and a length of $L=0.756$ $\mathrm{mm}$. However, to connect this coupler with the rest of the elements

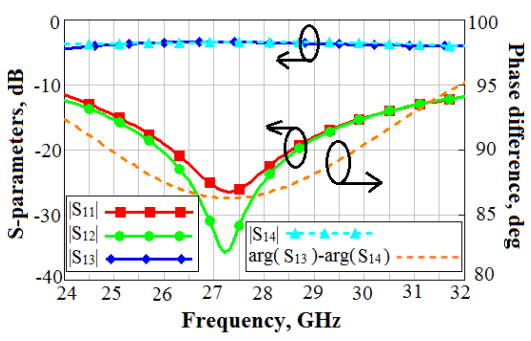

Fig. 2. The S-parameters of the coupler.

in the Butler matrix, the width of this feed line must be changed to achieve $50-\Omega$ characteristic impedance. This can be clearly seen in Fig. 1, where narrowing width $(W s=0.25 \mathrm{~mm})$ of the feed line ensures this transition from $20-\Omega$ to $50-\Omega$. A $3-\mathrm{dB}$ quadrature directional coupler with these parameters was simulated, and the simulated results demonstrate a phase imbalance of less than $\pm 4^{\circ}$, an amplitude imbalance of less than $0.4 \mathrm{~dB}$, and an isolation that exceeds $14 \mathrm{dBs}$ in the frequency range of $26-31.5 \mathrm{GHz}$ (Fig. 2).

\section{B. The Design of The Wideband Crossover}

A few designs of planar wideband crossovers, based on Lange coupler [24], have previously been demonstrated in [22, 25, 26]. However, these designs are difficult to fabricate because of the required electrical connections between different sections of the Lange coupler. A simpler design from fabrication perspective is a square patch with circular slots (see Fig. 1b) [27]. The wide operational band of the crossover is based on excitation of two resonances inside the square cavity. The first resonance is the resonance of modes $\mathrm{TM}_{100}$ and $\mathrm{TM}_{010}$ of the square patch. The second one is obtained by the circular slots.

The design has been optimized for a Rogers Ultralam 3850 laminate with a thickness of $0.1 \mathrm{~mm}$ for the band of $26-31 \mathrm{GHz}$. The length $L c$ is critical for the first resonance, and from (4) we calculate it to be $3.3 \mathrm{~mm}$ to get the first resonance at $26.7 \mathrm{GHz}$. The radius of the slot $R c$ and the widths $W 1=W 2$ help in achieving the second resonance. From simulations, $R c=1.3 \mathrm{~mm}$ and $W 1=W 2=0.15 \mathrm{~mm}$ have been obtained as the best values to place the second resonance close to the first resonance. A crossover with these dimensions has been simulated. The simulated results (Fig. 3) show that the crossover has an isolation of more than $15 \mathrm{~dB}$ and insertion loss of less than $1.5 \mathrm{~dB}$ within the range of 26-31.5 GHz. Due to the 


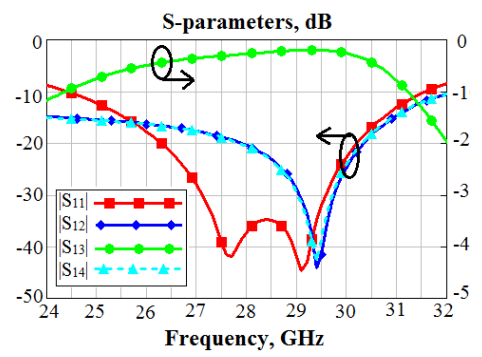

Fig. 3. The S-parameters of the crossover.

influence of the slot, we can see a slight shift $(\sim 3 \%)$ of the first resonance from the calculated value. It can be shown that in the absence of the slot, formula (4) gives very precise value of the resonance frequency of a square crossover. It is also observed in Fig. 3 , that isolated ports ( 2 and 4 ) do not have ideal isolation. This is due to some minor reflected currents going into those isolated ports. Nonetheless, the isolation is below $-15 \mathrm{dBs}$ for the entire band of interest.

\section{The Design of The Wideband Phase Shifter}

As per the requirement of Butler matrix feeding network, phase shifters must provide stable (with low phase imbalance) $45^{\circ}$ and $0^{\circ}$ phase shifts as compared to the signal coming from the wideband crossover. Many previous phase shifter designs use a straight transmission line as a reference. However, in the proposed Butler matrix implementation, the square crossover with slots has a group delay that is quite different from that of a straight transmission line. The ratio of the group delay of the crossover to the group delay of a $50-\Omega$ microstrip line is shown in Fig. 4 (curve 1). From this figure, it can be seen that the group delay of the crossover is more than twice of that of the microstrip line. Therefore, well-known wideband planar designs of Shiffman phase shifter [28], Lange coupler based

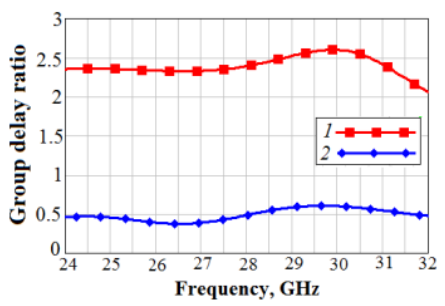

Fig. 4. The group delay ratio.

phase shifters [29, 30], or T-shaped open stub [31] and open-short stub phase shifters [32] cannot be used in the proposed Butler matrix design as they provide unit group delay ratio, whereas this particular crossover design requires 2.5 group delay ratio. Therefore, a new design is required to achieve the required group delay ratio and subsequently a stable phase shift over the entire BW.

In order to resolve the above-mentioned issue and achieve a low phase imbalance for the frequency range of 26-31 GHz, we have come up with a planar design of phase shifter which is a combination of series connected elements. An open-short phase shifter (Fig. 5a) can create stable phase shift (i.e. unit ratio of group delays) as compared with a $50-\Omega$ microstrip line in the frequency band of more than $20 \%$, as it has been shown in [32]. Series connection of two such phase shifters gives us the ratio of group delays equal to 2 . Additional group delay to get the required 2.35-2.6 ratio is possible through a Shiffman phase shifter (Fig. 5b), whose group delay ratio (compared with a $50-\Omega$ microstrip line) is shown in Fig. 4 (curve 2). Thus a novel combination of two open-short-stub phase shifter elements with the Shiffman phase shifter (Fig. 5c) provides the (a)

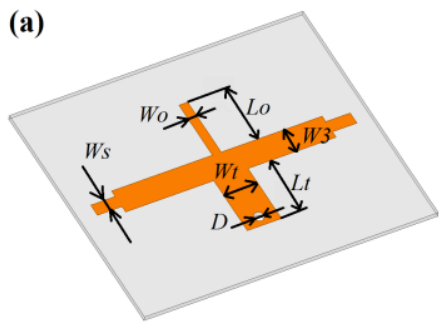

(c)

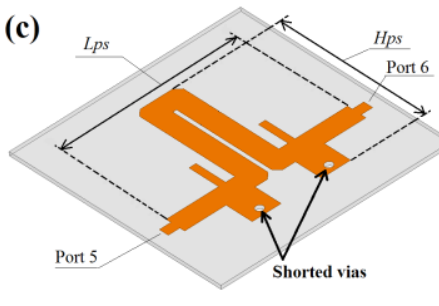

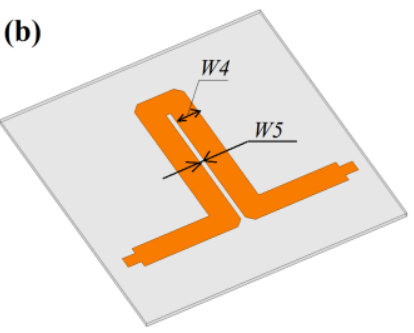

(b)

(d)

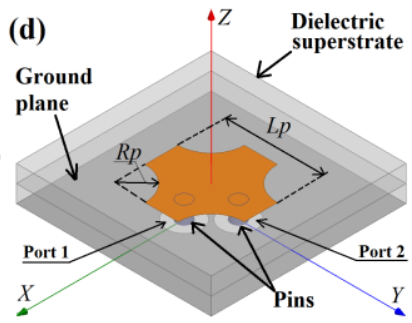

Fig. 5. (a) the open-short-stub phase shifter element geometry; (b) the Shiffman phase shifter geometry; (c) the overall proposed wideband phase shifter geometry; (d) the single element patch antenna element geometry.

required group delay ratio. This design allows to get a stable phase shift with low phase imbalance when the square patch crossover is a reference line.

Following conclusions can be deduced from the design process.

1. The width $W 3$ of the transmission line in the open-short stub phase shifter must have a characteristic impedance of 25-35 $\Omega$, provided the interconnecting lines have a characteristic impedance of $50-\Omega$ (represented by $W S$ in Fig. 5a). For the proposed design, $W 3$ $=0.52 \mathrm{~mm}$ which corresponds to $30-\Omega$.

2. The width of the transmission line $W 4$ in the Shiffman phase shifter is the same as the width $W 3$. The gap width $W 5$ should be 4-6 times smaller than the width $W 4$. For the proposed design, W5 $=0.1 \mathrm{~mm}$.

3. The widths $W o$ and $W t$ of the open and shorted stubs respectively must adhere to an impedance ratio of $\sim 3: 1$ to maximize the operational $\mathrm{BW}$ and to reduce the phase variation below $10 \%$. For the proposed design, an impedance ratio of 2.7:1 has been utilized, whereas $W o$ and $W t$ correspond to 62 and $23-\Omega$ respectively.

4. The lengths $L o$ and $L t$ of the open and shorted stubs have been calculated by the formula $\lambda /(8 \sqrt{\varepsilon})$, where $\lambda$ is the center wavelength of the operational frequency band, $\varepsilon$ is the permittivity of the phase shifter's substrate.

5. The height Hps of the Shiffman phase shifter is critical to achieve the required nominal of the phase shift.

The final dimensions of $0^{\circ}$ and $45^{\circ}$ phase shifter elements are listed in Table II. Phase shifter with the optimized dimensions has been simulated and the results are shown in Fig. 6. It can be seen that the phase shifter has an insertion loss of less than $0.6 \mathrm{~dB}$ for the entire range of 26-31.5 GHz. Phase shift of the wideband phase shifter has been calculated by subtracting the phase of $\mathrm{S}_{13}$ (ports for the TABLE II

DiMENSIONS (IN MM) OF $0^{\circ}$ AND $45^{\circ}$ PHASE SHIFTERS

\begin{tabular}{||c|c|c|c|c|c|c|c|c||}
\hline \hline $\begin{array}{c}\text { Phase } \\
\text { shift }\end{array}$ & Lps & Hps & Wo & Lo & Wt & Lt & W3 & D \\
\hline $0^{\circ}$ & 4.7 & 4.11 & 0.18 & 0.84 & 0.75 & 0.74 & 0.52 & 0.2 \\
\hline $45^{\circ}$ & 4.5 & 4.3 & 0.18 & 0.775 & 0.7 & 0.775 & 0.52 & 0.2 \\
\hline
\end{tabular}

crossover) from phase of $\mathrm{S}_{56}$ (ports for the phase shifter). From Fig. 6 we can see that phase deviation of the phase shifter is less than $\pm 5^{\circ}$ from the required $0^{\circ}$ and $45^{\circ}$ phase shifts for the entire frequency range of 26-31.5 GHz. In the following section, with simulated and 


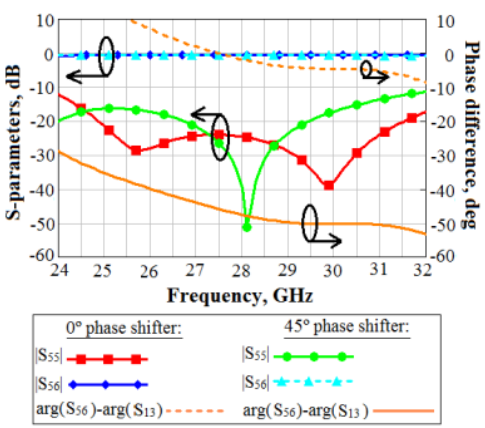

Fig. 6. The S-parameters of the phase shifter.

measured results for a complete design of antenna array, we will show that the $\pm 5^{\circ}$ phase deviation does not affect the BSR and the SLL.

\section{The Design of The Wideband Radiating Element}

For this particular design, we need a wide band antenna element that can support two orthogonal linear polarizations over the frequency range of $26-31.5 \mathrm{GHz}$ and have a broad radiation pattern. One possible antenna that satisfies the requirements on dualpolarization operational mode as well as broad radiation pattern is a rectangular or circular patch. But, such patch antennas can typically provide less than $7 \% \mathrm{BW}$ [23]. In the proposed patch design (a square patch antenna with semi-circular cut-outs) [33], as shown in Fig. $5 \mathrm{~d}$, can fulfill the large BW requirement. The patch antenna is in the form of a square plate of length $L p=2.65 \mathrm{~mm}$ that has angled circular cutouts of the radii $R p=0.95 \mathrm{~mm}$. The radiating element and the superstrate have been implemented on a Rogers RO4533 laminate, which has a permittivity of 3.3 , loss tangent of 0.0025 , and a thickness of $0.76 \mathrm{~mm}$. The patch is excited by two metallic pins with diameters of $0.416 \mathrm{~mm}$, which are located at distances of 0.78 $\mathrm{mm}$ from the center of the patch (along the $\mathrm{X}$ and $\mathrm{Y}$-axes), through circular holes with a diameter of $1 \mathrm{~mm}$ in the metallic ground plane.

The simulated results for this patch antenna are shown in Fig. 7. Due to symmetricity of the patch in $Z X$ and $Z Y$-planes, $\left|\mathrm{S}_{11}\right|=\left|\mathrm{S}_{22}\right|$ and $\left|\mathrm{S}_{12}\right|=\left|\mathrm{S}_{21}\right|$. From Fig. 7, we can see that the antenna is well matched for the desired frequency range and the isolation between the two ports is better than $12 \mathrm{~dB}$.

\section{RESUlTs AND Discussions}

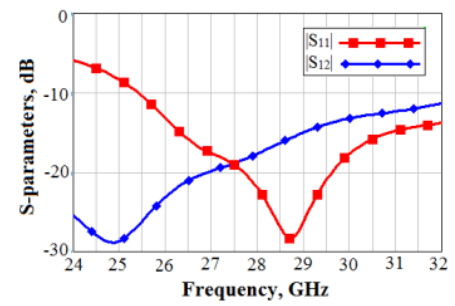

Fig. 7. The S-parameters of the patch element.

\section{A. The Design of The Antenna Array}

A 16 elements antenna array has been designed which requires three boards (Fig. 8). The $1^{\text {st }}$ board, based on Ultralam 3850 laminate, contains the feeding network, the $2^{\text {nd }}$ board has the planar 16 element $(4 \times 4)$ radiating patches and the $3^{\text {rd }}$ is the superstrate board. Both, the second and third board, are based on Rogers RO4533 laminate. Each board has a size of $70 \times 120 \mathrm{~mm}^{2}$. The patch inter-element spacing is $5.5 \mathrm{~mm}(0.57$ wavelength for the frequency of $31.4 \mathrm{GHz}$ ) in both $\mathrm{X}$ and $\mathrm{Y}$-directions. The electrical contact between the feeding network and the radiating patches is created by metallized vias between the $1^{\text {st }}$ and the $2^{\text {nd }}$ board.

For simultaneous operation with two orthogonal linear polarizations, we feed the radiating patches by two identical independent Butler matrices (Fig. 9 (a)). Each Butler matrix has four ports to create four beams. Each output microstrip line from the

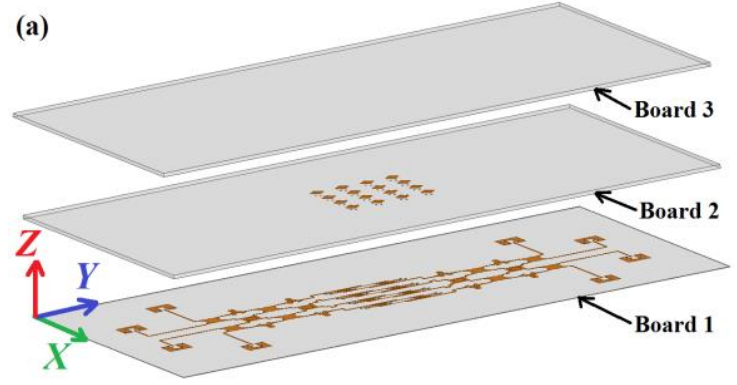

(b)

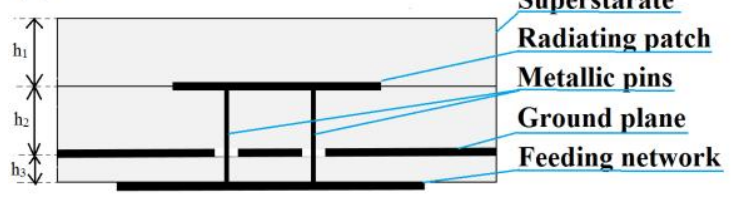

Fig. 8. (a) the boards' view of 16-elements antenna array; (b) PCB stack up view $\left(\mathrm{h}_{1}=\mathrm{h}_{2}=0.76 \mathrm{~mm}, \mathrm{~h}_{3}=0.1 \mathrm{~mm}\right)$.

Butler matrix feeds a 4-element linear patch array via a power divider (Fig. 9 (b)) with non-uniform amplitude distribution. The normalized amplitudes at the outputs of the power divider are: $\mathrm{A} 2=\mathrm{A} 3=1, \mathrm{~A} 1=\mathrm{A} 4=0.6$. The non-uniform amplitude distribution is used to provide low SLL in the radiation pattern in the plane that is orthogonal to the plane of beam scanning. When ports 1-4 are excited, the antenna array operates with main polarization of the electrical field in the Y-direction. When ports 5-8 are excited, the main polarization of electrical field is in the X-direction.

\section{B. $\quad$ Simulated and Measured Results}

A prototype of the antenna array (Fig. 10) has been fabricated and measured in a far field chamber. The fabrication process includes drilling vias in the $1^{\text {st }}$ and the $2^{\text {nd }}$ boards with subsequent metallization of the vias. The final manufacturing is performed by bonding all the three boards using Rogers $4450 \mathrm{~F}$ bondply with a

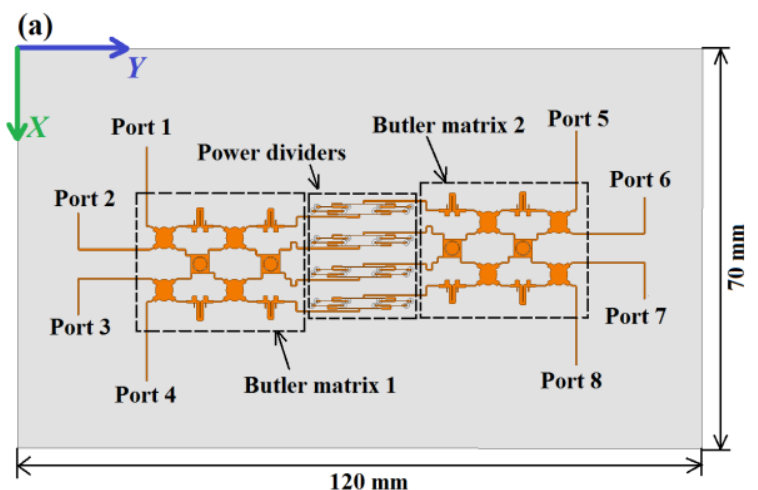

(b)

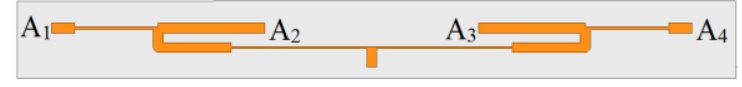

Fig. 9. (a) the feeding network of the dual-polarized antenna array; (b) the power divider. 


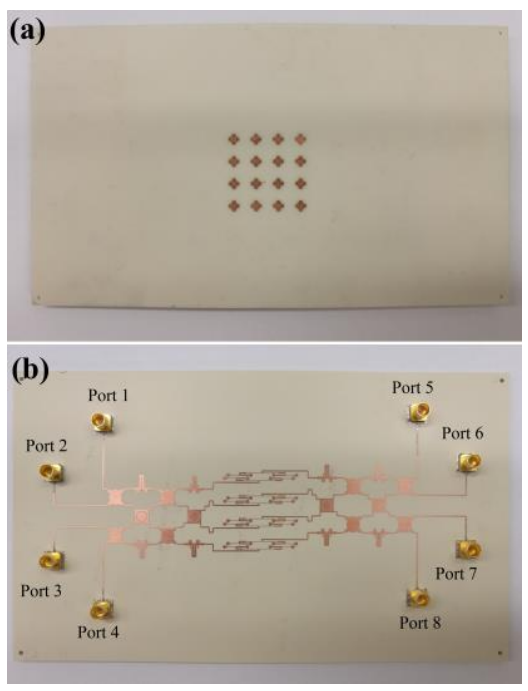

Fig. 10. Photo of the fabricated prototype: (a) layer of radiating patches; (b) layer of the feeding network.

thickness of $0.1 \mathrm{~mm}$ as prepreg. The prototype is fed by mini-SMP connectors. During the measurements, all unused connectors are loaded by $50-\Omega$ terminations.

Simulated and measured S-parameters $\left(\mathrm{S}_{\mathrm{nm}} ; \mathrm{n} \vee \mathrm{m}=1,2, \ldots, 8\right)$ of the array are presented in Fig. 11. From Fig. 11 (a), we can see that the reflection coefficients for ports $1-4$ are less than $-10 \mathrm{~dB}$ for the frequencies of $26-31.4 \mathrm{GHz}$ (the $\mathrm{BW}$ is $19 \%$ ). The same $\mathrm{BW}$ we obtain for ports 5-8. Fig. 11 (b) show isolation between the ports of Butler matrix 1 (note that $\left|\mathrm{S}_{12}\right|=\left|\mathrm{S}_{21}\right|,\left|\mathrm{S}_{13}\right|=\left|\mathrm{S}_{31}\right|,\left|\mathrm{S}_{14}\right|=\left|\mathrm{S}_{41}\right|$ ). From this figure, we can see that isolation is more than $15 \mathrm{~dB}$ for the working frequency band. Measurements show that isolation between ports 2$3,2-4$ and 3-4 is also more than $15 \mathrm{~dB}$. Measured curves of isolation
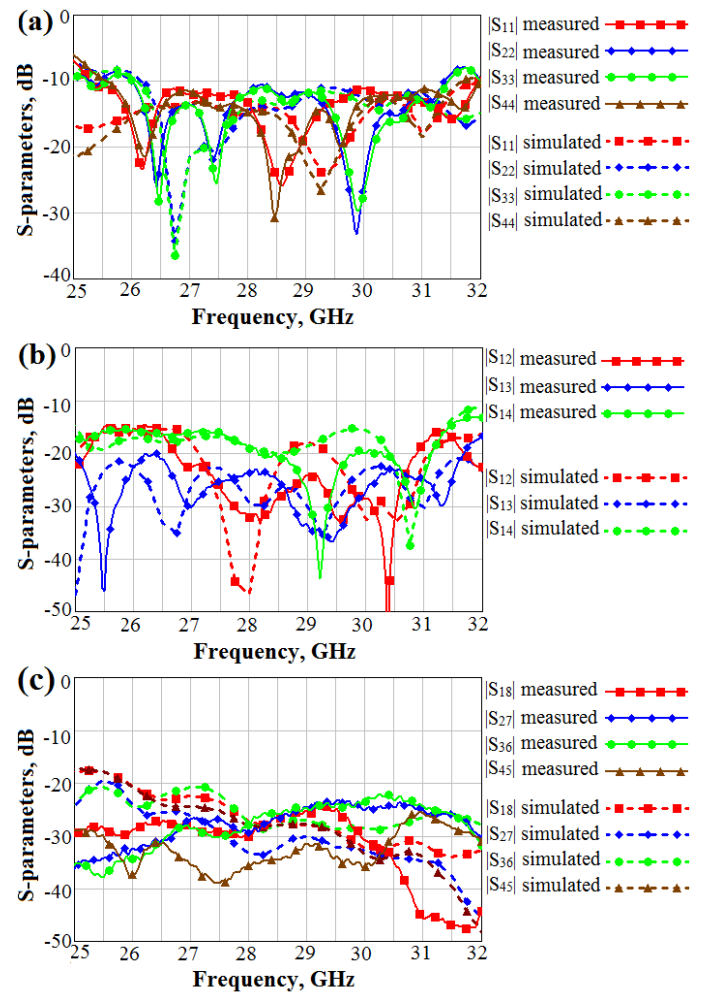

Fig. 11. (a) reflection coefficients for ports 1-4; (b) isolation between ports $1-2,1-3,1-4 ;$ (c) isolation between ports 1-8, 2-7, 3-6, 4-5. between ports of Butler matrix 2 are similar to the curves of isolation between ports of Butler matrix 1, therefore they are not shown in a separate figure. Fig. 11 (c) shows isolation between ports of the Butler matrixes 1 and 2. Isolation between ports 1-8, 2-7, 3-6 and 4-5 is better than $25 \mathrm{~dB}$ in the working frequency band. For other ports, isolation between two Butler matrixes is more than $30 \mathrm{~dB}$.

Fig. 12 shows the radiation patterns of the antenna array in the XZ-plane at frequencies of $26,28.5$, and $31 \mathrm{GHz}$ when different ports are excited. The angle $\theta$ in the figure is measured from the Zaxis. From Fig. 12 we can see that the directions of the main beam are $-42^{\circ}\left(-42^{\circ}\right),-13^{\circ}\left(-13^{\circ}\right), 13^{\circ}\left(13^{\circ}\right)$ and $42^{\circ}\left(42^{\circ}\right)$ when port $2(6), 4$ (8), 1 (5), and 3 (7) are excited, respectively. Maximum gain is 12 and $9 \mathrm{dBi}$ for the beams with $\pm 13^{\circ}$ and $\pm 42^{\circ}$ main directions, respectively. The SLL in XZ-plane is -10 and $-8 \mathrm{~dB}$ for the beams with $\pm 13^{\circ}$ and $\pm 42^{\circ}$ main directions, respectively. Due to non-uniform amplitude power dividers of the feeding network, the SLL in the YZplane is at least $15 \mathrm{~dB}$. Measurements show that the crosspolarisation levels are $16 \mathrm{~dB}$ lower as compared to the maximum of the co-polarised patterns, for all ports inside the operating frequency band of 26-31.4 GHz.

From the simulated and measured results we can see that the proposed design of the antenna array demonstrates wide impedance BW as well as wide BW for stable beam steering.

Additional investigation has been performed on the efficiency of the array. This investigation shows that the efficiency is in the range of $29-36 \%$ inside the operational frequency band. It is worth mentioning here that the efficiency of a single radiating element is more than $90 \%$ inside the operational band [33]. Thus, the microstrip feed network losses $(\sim 4 \mathrm{~dB})$ at such high frequencies are responsible for such relatively low efficiency.

Note that BFN has been realized in microstrip line implementation that leads to its potential radiation and interference with electronics placed behind the antenna array. To avoid the interference issue and
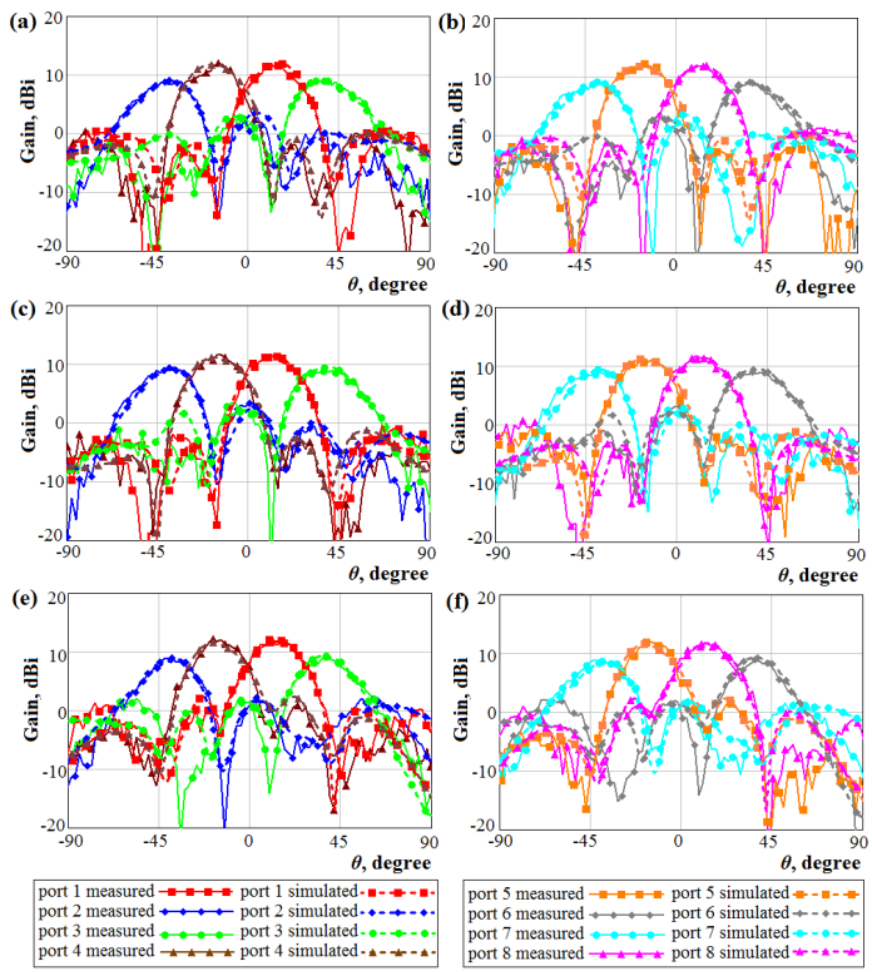

Fig. 12. Radiation patterns of the antenna at the frequency of (a, b) $26 \mathrm{GHz}$; (c, d) $28.5 \mathrm{GHz}$; (e, f) $31 \mathrm{GHz}$. 
get high isolation, the BFN can be implemented as a stripline where an additional board with ground plane is added to the bottom of the board 1. Investigation of a stripline based BFN shows that it can provide the same BW and coupling characteristics as its microstrip counterpart, without distorting the radiation pattern.

\section{CONCLUSIONS}

In this paper, we propose the design of a 16-element antenna array covering the bands 26-31.4 GHz, which operates with two orthogonal linear polarizations and provides $\pm 42^{\circ}$ beam switching. The antenna array is based on a Butler matrix feed network and wideband patch radiating elements. The Butler matrix design is implemented by planar wideband crossovers, couplers and phase shifters. The proposed design provides better operating bandwidth among the published switched-beam Butler matrix based antenna array designs. The construction is fabricated by three boards of lowcost Rogers laminates.

\section{REFERENCES}

[1] "5G spectrum recommendations," 5G Amer., Bellevue, WA, USA, White Paper, Apr. 2017. [Online]. Available: http://www.5gamericas.org/files/9114/9324/1786/5GA_5G_Spectrum_ Recommendations_2017_FINAL.pdf

[2] W. Hong et al., "Multibeam Antenna Technologies for 5G Wireless Communications," IEEE Trans. Antennas Propagat., vol. 65, no. 12, pp. 6231-6249, Dec. 2017.

[3] K. Fujimoto, Mobile Antenna Systems Handbook, Third edition. Norwood, MA, USA: Artech house, 2008.

[4] I. Uchendu and J. Kelly, "Survey of Beam Steering Techniques Available for Millimeter Wave Applications," PIER, vol. 68, pp. 35-64, 2016.

[5] "AWMF-0157 Product data sheet," Anokiwave, San Diego, CA, USA.

[6] S.-C. Gao, L.-W. Li, M.-S. Leong, and T.-S. Yeo, "Integrated multibeam dual-polarised planar array," in IEE Proc.-Microw., Antennas and Propag., vol. 148, no. 3, pp. 174-178, June 2001.

[7] G. Exposito-Dominguez, J. M. Fernandez-Gonzalez, P. Padilla, and M. Sierra-Castaner, "Dual circular polarized steering antenna for satellite communications in x band," PIER, vol. 122, pp. 61-76, 2012.

[8] M. M. Cao, X. Wang, X. N. Huo, X. F. Wang and S. X. Wang, "A novel dual band and dual circularly-polarized multi-beam antenna based on Butler matrix," in Proc. IEEE-APS APWC, Verona, 2017, pp. 64-66.

[9] C. Dall'Omo, T. Monediere, B. Jecko, F. Lamour, I. Wolk, and M. Elkael, "Design and realization of a $4 \times 4$ microstrip Butler matrix without any crossing in millimeter waves," Microw. Opt. Technol. Lett., vol. 38 , no. 6, pp. 462-465, Sept. 2003.

[10] C. H. Tesng, C. J. Chen, and T. H. Chu, "A low-cost 60-GHz switched beam patch antenna array with Butler matrix network," IEEE Antennas Wireless Propag. Lett., no. 7, pp. 432-435, July 2008.

[11] W. F. Moulder, W. Khalil, and J. L. Volakis, "60-GHz TwoDimensionally Scanning Array Employing Wideband Planar Switched Beam Network," IEEE Antennas Wireless Propag. Lett., vol. 9, pp. 818-821, 2010.

[12] C. Rusch, C. Karcher, S. Beer, and T. Zwick, "Planar Beam Switched Antenna with Butler Matrix for $60 \mathrm{GHz}$ WPAN," in Proc. 6th European Conf. on Antennas and Propag. (EUCAP), Prague, Czech Republic, 2012, pp. 2794-2797.

[13] C. E. Patterson, W. T. Khan, G. E. Ponchak, G. S. May, and J. Papapolymerou, "A 60-GHz active receiving switched-beam antenna array with integrated Butler matrix and GaAs amplifiers," IEEE Trans. Microwave Theory Tech., vol. 60, no. 11, pp. 3599-3607, Nov. 2012.
[14] N. Tiwari and T. Rama Rao, "A Switched Beam Antenna Array with Butler Matrix Network Using Substrate Integrated Waveguide Technology for $60 \mathrm{GHz}$ Communications," in Proc. Int. Conf. on Advances in Computing, Communications and Informatics (ICACCI), Kerala, India, 2015, pp. 2152-2157.

[15] Qing-Ling Yang, Yong-Ling Ban, Kai Kang, Chow-Yen-Desmond Sim and Gang Wu, "SIW Multibeam Array for 5G Mobile Devices", IEEE Access, vol. 4, pp. 2788-2796, June 2016.

[16] A. T. Alreshaid, M. S. Sharawi, S. Podilchak, and K. Sarabandi, "Compact millimeter-wave switched-beam antenna arrays for short range communications," Microwave and Optical Technology Letters, vol. 58, no. 8, pp. 1917-1921, Aug. 2016.

[17] P. Pan, H. Wang, Z. Zhao, and W. Zhang, "How Many Antenna Arrays Are Dense Enough in Massive MIMO Systems," IEEE Trans. Vehic. Tech., vol. 67, no. 4, pp. 3042-3053, April 2018.

[18] N. Sutton and D. S. Filipovic, "Design of a K- thru Ka-band modified Butler matrix feed for a 4-arm spiral antenna," in Proc. 2010 Loughborough Antennas \& Propagation Conf., Loughborough, UK, Nov. 2010, pp. 521-524.

[19] C. Caloz, A. Sanada, and T. Itoh, "A Novel Composite Right-/LeftHanded Coupled-Line Directional Coupler With Arbitrary Coupling Level and Broad Bandwidth," IEEE Trans. Microwave Theory Tech., vol. 52, no. 3, pp. 980-992, March. 2004.

[20] R. K. Mongia, I. J. Bahl, P. Bhartia, J. Hong, RF and Microwave Coupled-Line Circuits. Norwood, MA, USA: Artech house, 2007.

[21] K.-L. Chan, F. A. Alhargan, S. R. Judah, "A quadrature-hybrid design using a four-port elliptic patch," IEEE Trans. Microwave Theory Tech., vol. 45, no. 3, pp. 307-310, March 1997.

[22] T. N. Kaifas and J. N. Sahalos, "On the Design of a Single-Layer Wideband Butler Matrix for Switched-Beam UMTS System Applications," IEEE Antennas Propagat. Magazine, vol. 48, no. 6, pp. 193-204, Dec. 2006.

[23] J. R. James and P. S. Hall, Handbook of Microstrip Antennas. London, UK: Peter Peregrinus Ltd., 1989.

[24] J. Lange, "Interdigitated Stripline Quadrature Hybrid," IEEE Trans. Microwave Theory Tech., vol. 17, no. 12, pp. 1150-1151, Dec. 1969.

[25] M. Daneshmand, R. R. Mansour, P. Musavi, S. Choi, B. Yassini, A. Zybura, and M. Yu, "Integrated Interconnect Networks for RF Switch Matrix Applications," IEEE Trans. Microwave Theory Tech., vol. 53, no. 1, pp. 12-21, Jan. 2005.

[26] T. N. Kaifas and J. N. Sahalos, "A $4 \times 4$ Butler matrix optimized for UMTS applications," Microwave and Optical Technology Letters, vol. 49, no. 3, pp. 585-588, March 2007.

[27] B. Henin, and A. Abbosh, "Wideband planar microstrip crossover with high power handling capability and low distortion," Microwave and Optical Tech. Lett., vol. 55, no. 2, pp. 439-443, Feb. 2013.

[28] B. M. Schiffman, "A new class of broad-band microwave $90^{\circ}$ phase shifters," IRE Trans. Microw. Theory Tech., vol. 6, no. 2, pp. 232-237, Apr. 1958.

[29] G. Boyacioglu, Ş. Demir, "Wideband phase shifter design using Lange coupler and radial stubs," in Proc. Mediterranean Microwave Symposium (MMS), Guzelyurt, Cyprus, Aug. 2010, pp. 36-39.

[30] S. Sarkooyeh, M. Salimi, "An Innovative Ultra Wideband Microstrip Phase Shifter Based on the LANGE Coupler," Int. J. of Science and Engineering Applications, vol. 4, no. 2, pp. 43-45, Mar.-Apr. 2015.

[31] S. Y. Zheng, W. S. Chan, and K. F. Man, "Broadband phase shifter using loaded transmission line," IEEE Microw. Wireless Compon. Lett., vol. 20, no. 9, pp. 498-500, Sep. 2010.

[32] M.-D. Wei, P. Gjurovski and R. Negra, " $90^{\circ}$ Broadband Asymmetrical Open-Short-Stub Phase Shifter with Inductance Compensation," in Proc. 46th European Microwave Conference (EuMC), London, UK, Oct. 2016, pp. 979-982.

[33] K. Klionovski and A. Shamim, "Physically Connected Stacked Patch Antenna Design with $100 \%$ Bandwidth," IEEE Antennas Wireless Propag. Lett., vol. 16, pp. 3208-3211, 2017. 